\title{
ASSOCIATION OF IATROGENIC GALL BLADDER PERFORATION IN PATIENTS UNDERGOING CHOLECYSTECTOMY.
}

\author{
DR. ALI HUSSAIN, MBBS \\ NISHTAR HOSPITAL, MULTAN, PAKISTAN. \\ DR. ABDUL MUNIM AKRAM, MBBS \\ NISHTAR HOSPITAL, MULTAN, PAKISTAN. \\ DR. KAINAT SADIA, MBBS \\ NISHTAR HOSPITAL, MULTAN, PAKISTAN.
}

\begin{abstract}
Background: Laparoscopic cholecystectomy is one of the most commonly performed laparoscopic surgery around the world providing low cost and morbidity treatment for gall bladder diseases. Iatrogenic gallbladder perforation is a common complication of laparaoscopic cholecystectomy. This study was conducted to establish the frequency of iatrogenic gall bladder perforation during laparoscopic cholecystectomy in our patients. Objective: To determine the frequency of iatrogenic gall bladder perforation during laparoscopic cholecystectomy in patients operated in surgical department of Nishtar Hospital Multan. Material and methods; A total of 292 patients undergoing laparoscopic cholecystectomy were recruited in our study. Iatrogenic gallbladder perforation during the surgery was noted in a proforma and data was analyzed by using SPSS version 20. Results; Of these 292 study cases, $87(40.7 \%)$ were male patients and $127(59.3 \%)$ were female patients. Our study results have indicated that majority of our patients i.e. $127(59.3 \%)$ were aged more than 40 years. Iatrogenic gallbladder perforation was present in $40(18.7 \%)$ of our study cases.
\end{abstract}

Conclusion; Laparoscopic cholecystectomy in patients with cholelithiasis is quite safe, reliable and effective procedure as frequency of iatrogenic gallbladder perforation was low in our study cases. However, iatrogenic gallbladder perforation was significantly associated with increasing age, hypertension, and prolonged duration of surgery.

Keywords; iatrogenic gallbladder perforation, laparoscopic cholecystectomy, cholelithiasis.

DOI: $10.7176 / \mathrm{JMPB} / 54-15$

Publication date: April $30^{\text {th }} 2019$

\section{INTRODUCTION}

Laparoscopic cholecystectomy performed for the first time in 1987 by Movert in France is now gold standard for the treatment of symptomatic gallstones. It has replaced the open technique for the majority of 770,000 cholecystectomies performed in US each year.(1,2)Laparoscopic cholecystectomy is a commonly performed procedure in general surgical units all over the world. The inherent advantages of the procedure that include low post-operative morbidity with significant economic impact were recognized after few years of its introduction.(3) In 1992 the consensus statement from national institute of health (NIH) conference accepted LC as the treatment of choice for patients with symptomatic gallstones.(4) Laparoscopic cholecystectomy has been the gold standard for symptomatic gall stones for 15 years. Over the time the rate of common bile duct injuries from LC has declined. Unfortunately the incidence of spillage of gall stones has remained unchanged. Likely any other procedure LC has known complications of which iatrogenic perforation of the gall bladder (PGB) during laparoscopic cholecystectomy (LC) leads to spillage of bile and gall stones into the peritoneal cavity which can result in serious post-operative infection.(5) 
Gallbladder perforation with stone spillage into the peritoneal cavity is more frequent with laparoscopic cholecystectomy as compared with open cholecystectomy. Early reports on laparoscopic cholecystetomy stated that stones left in peritoneal cavity had no deleterious effect. Altough the incidence of split gallstones and their complications are low they are of large variety. Thus, it makes a significant problem. The variety of complications caused by gallstones may range from simple surgical site infection to more serious froms like broncholithiasis(6) . Zubair et al(7) from karachi reported $25.5 \%$ istrogenic gallbladder perforations in patients undergoing laproscopic cholecystectomy while hui et al(8) from USA reported $36 \%$ iatrogenic gallbladder perforations.

The aim of this study is to determine the frequency of iatrogenic gallbladder perforations in patients undergoing laparoscopic cholecystectomy in our local population. The results will report current magnitude of problem in our local population and help to decrease disease morbidity in such patients.

\section{MATERIAL AND METHODS}

A total 292 patients undergoing laparoscopic cholecystectomy were included in the study. Patients having jaundice and common bile duct stones, previous history of abdominal surgeries, Hepatitis B and C positive cases, alcoholic Abuse (confirmed on history) and pregnant ladies were excluded from our study. Informed consent was taken from all participants after explaining the objectives of study, ensuring complete confidentiality and the fact that there is no risk involved to patient while taking part in study. All patients were operated upon by same surgeon with 5 years post fellowship experience. All patients were observed during surgery for iatrogenic gallbladder perforations anytime during the procedure. The required information including the demographic profile was collected by a structured questionnaire. Data was analyzed by using SPSS version 20. Mean and standard deviation was calculated for age, BMI, and duration of surgery. Frequency and percentage were calculated for categorical variables like gender, age groups, diabetes, hypertension, residential status, obesity and iatrogenic gall bladder perforation.

\section{RESULTS}

A total of 29 study cases meeting inclusion criteria of our study were included in this study. Of these 292 study cases, $123(42.1 \%)$ were male patients and $169(57.9 \%)$ were female patients. Mean age of our study cases is $43.75 \pm 9.21$ years (with minimum age was 29 years while maximum age was 60 years). Our study results have indicated that majority of our patients i.e. 157(53.8\%) were aged less than 45 years. (Table No. 1 and Figure no 2 ). Of these 292 study cases, 93 (31.8\%) were diabetic and history of hypertension was positive in 131(44.9\%). Obesity was present in $55(18.8 \%)$ of our study cases. Mean duration of surgery was noted $55.57 \pm 14.82$ minutes. Iatrogenic gallbladder perforation was present in $61(20.9 \%)$ of our study cases. Majority of patients $197(67.5 \%)$ were resident of rural areas while only $95(32.5 \%)$ were from urban areas.

\section{DISCUSSION}

A total of 292 study cases meeting inclusion criteria of our study were included in this study. Of these 292 study cases, $123(42.1 \%)$ were male patients and $169(57.9 \%)$ were female patients. A study conducted by Channa et al ${ }^{9}$ from Jamshoro also reported high female gender predominance with male to female ratio was 1:3 which is in compliance with that of our study results. Samad et al ${ }^{10}$ from Hyderabad also reported $87 \%$ female gender preponderance which is in compliance with our study results. A Study conducted by Rahman et al ${ }^{11}$ from Peshawar also reported male to female ratio was 1:2 which is in compliance with our study results. Sattar et al ${ }^{12}$ from Karachi also reported $73 \%$ female gender predominance in patients with cholelithiasis which is in compliance with our study results.

Mean age of our study cases is $43.75 \pm 9.21$ years (with minimum age was 29 years while maximum age was 60 years). Mean age of the male patients was $46.67 \pm 8.06$ years while that of female patients was 44.31 \pm 8.81 years. $(\mathrm{p}=0.049)$. our study results have indicated that majority of our patients i.e. $157(53.8 \%)$ were aged more than 40 years. A study conducted by Channa et al ${ }^{9}$ from Jamshoro also reported similar results.

Furthermore Channa et al ${ }^{9}$ also found that female patients were significantly younger than that of male patients which is in compliance with our study results. Samad et al(84)from Hyderabad also reported 54.8 years mean age of the patients with cholelithiasis which is in compliance with our study results. 
A Study conducted by Rahman et al ${ }^{11}$ from Peshawar also reported 55 years mean of the patients with cholelithiasis which is close to our study results. Sattar et al ${ }^{12}$ from Karachi also reported 48 years mean age which is close to our study results.

Of these 214 study cases, $93(31.8 \%)$ were diabetic and history of hypertension was positive in $131(44.9 \%)$. Mean body mass index of our study cases was $25.08 \pm 2.16 \mathrm{~kg} / \mathrm{m}^{2}$ while obesity was present in 40 $(18.7 \%)$ of our study cases. Mean duration of hospitalization was $5.18 \pm 1.35$ days and mean duration of surgery was noted $57.53 \pm 14.82$ minutes. Ozkardeş et al ${ }^{13}$ reported mean post - operative hospital stay to be $5.2 \pm 1.40$ days in patients with laparoscopic cholecystectomy which is close to our study results. Gutt et al ${ }^{14}$ reported Mean length of hospital stay 5.4 days in patients with laparoscopic cholecystectomy which is in compliance with our study results. Jamil et al ${ }^{15}$ reported mean hospital stay was $3.47 \pm 1.40$ days which is slightly less than that being reported in our study. Ozkardeş et al ${ }^{13}$ reported operative time in laparoscopic cholelcystectomy was $67 \pm 28.515$ ( $\mathrm{min}$ ) which is close to our study results. Iatrogenic gallbladder perforation was present in $61(20.9 \%)$ of our study cases.

Naqvi et al ${ }^{16}$ from Nawabshah reported $36 \%$ which is slightly higher than that of our study results. Rao et al ${ }^{17}$ studied 1038 patients undergoing laparoscopic cholecystectomy in Jamshoro. Iatrogenic gall bladder perforation was present in $226(21.77 \%)$ patients which is close to the results of our study. This incidence is slightly greater than described in a Canadian Multicenter study $(9 \%){ }^{18}$. A study conducted by FlorinT found out iatrogenic perforaton gallbladder with a frequency of $18.19 \%{ }^{19}$ which is comparable to the results of our study. Another study conducted by Iemy hussen ${ }^{20}$ showed frequency of iatrogenic gallbladder perforation at $29 \%$ which is higher than our study results.

\section{CONCLUSION;}

Laparoscopic cholecystectomy in patients with cholelithiasis is quite safe, reliable and effective procedure as frequency of iatrogenic gallbladder perforation was low in our study cases, However, iatrogenic gallbladder perforation was significantly associated with increasing age, hypertension, and prolonged duration of surgery.

\section{$\underline{\text { References }}$}

1. Wu XD, Tian X, Liu MM, Wu L, Zhao S, Zhao L. Meta-analysis comparing early versus delayed laparoscopic cholecystectomy for acute cholecystitis. British Journal of Surgery. 2015;102(11):1302-13.

2. Song G-M, Bian W, Zeng X-T, Zhou J-G, Luo Y-Q, Tian X. Laparoscopic cholecystectomy for acute cholecystitis: early or delayed?: Evidence from a systematic review of discordant meta-analyses. Medicine. 2016;95(23).

3. Yethadka R, Shetty S, Vijayakumar A. Attitudes and Practices of Surgeons towards Spilled Gallstones during Laparoscopic Cholecystectomy: An Observational Study. International scholarly research notices. 2014;2014.

4. Khan MS, Khatri MA, Khan MS, Oonwala ZG. Knowledge and practices of general surgeons and residents regarding spilled gallstones lost during laparoscopic cholecystectomy: a cross sectional survey. Patient safety in surgery. 2013;7(1):27.

5. Virupaksha S. Consequences of spilt gallstones during laparoscopic cholecystectomy. Indian Journal of Surgery. 2014;76(2):95-9.

6. Nooghabi AJ, Hassanpour M, Jangjoo A. Consequences of Lost Gallstones During Laparoscopic Cholecystectomy: A Review Article. Surgical Laparoscopy Endoscopy \& Percutaneous Techniques. 2016;26(3):183-92.

7. Zubair M, Habib L, Mirza MR, Channa MA, Yousuf M. Iatrogenic gall bladder perforations in laparoscopic cholecystectomy: an audit of 200 cases. Mymensingh medical journal : MMJ. 2010;19(3):422-6. 8. Hui TT, Giurgiu DI, Margulies DR, Takagi S, Iida A, Phillips EH. Iatrogenic gallbladder perforation during laparoscopic cholecystectomy: etiology and sequelae. The American surgeon. 1999;65(10):944-8.

9. Channa NA, Khand FD, Bhanger MI, Leghari MH. Surgical incidence of Cholelithiasis in Hyderabad and adjoining areas (Pakistan). Pakistan Journal of Medical Sciences. 2004;20(1):13-7.

10. Samad A. Gall bladder carcinoma in patients undergoing cholecystectomy for cholelithiasis. JOURNAL-PAKISTAN MEDICAL ASSOCIATION. 2005;55(11):497.

11. Rahman A, Shah S, Khan N, Arif A, Asadullah SM. Frequency of carcinoma gall bladder in patients undergoing surgery for chronic cholecystitis with cholelithiasis. Pak J Med Sci. 2006;14(1). 
12. Sattar I, Aziz A, Rasul S, Mehmood Z, Khan A. Frequency of infection in cholelithiasis. J Coll Physicians Surg Pak. 2007;17(1):48-50.

13. Özkardeş AB, Tokaç M, Dumlu EG, Bozkurt B, Çiftçi AB, Yetişir F, et al. Early versus delayed laparoscopic cholecystectomy for acute cholecystitis: a prospective, randomized study. International surgery. 2014;99(1):56-61.

14. Gutt CN, Encke J, Köninger J, Harnoss J-C, Weigand K, Kipfmüller K, et al. Acute cholecystitis: early versus delayed cholecystectomy, a multicenter randomized trial (ACDC study, NCT00447304). Annals of surgery. 2013;258(3):385-93.

15. Jamil M, Niaz K, Ali A, Saeed S. Laparoscopic cholecystectomy for acute cholecystitis: early versus delayed. Rawal Med J. 2014;39(2):199-202.

16. Naqvi SQH, Mangi IH, Dahri FJ, Khaskheli QA, Akhund AA. Frequency of carcinoma of gall bladder in patients with cholelithiasis. Gomal Journal of Medical Sciences. 2005;3(2).

17 Rao AMK, Dalwani AG, Sushel C, Shaikh U. SPILLED BILE AND GALLSTONES; THE CONSEQUENCES DURING LAPAROSCOPIC CHOLECYSTECTOMY: EXPERIENCE AT LIAQUAT UNIVERSITY HOSPITAL. Professional Medical Journal. 2016;23(8).

18. Litwin D, Girotti M, Poulin E, Mamazza J, Nagy A. Laparoscopic cholecystectomy: trans-Canada experience with 2201 cases. Canadian journal of surgery Journal canadien de chirurgie. 1992;35(3):291-6. 19. Florin T. Management of Spilled Stones duringLaparoscopic Cholecystectomy. World Journal of Laparoscopic Surgery. 2010;3(2):103-7.

20. HUSSEN IEMY. MANAGEMENT OF DROPPED GALLSTONES DURING LAPAROSCOPIC CHOLECYSTECTOMY. AAMJ. 2014;12(3). 